\title{
Fluorescent test accurately predicts leak of ischemic colon anastomosis in rats ${ }^{1}$
}

\author{
Laura Moschetti', Tiago Leal Ghezzi", Belisa Gomes Müller'II, Adriano Basso Dias'v, Oly Campos \\ Corletav
}

'MSc, Postgraduate Program in Surgical Sciences, Universidade Federal do Rio Grande do Sul (UFRGS), Porto Alegre-RS, Brazil. Conception and design of the study; surgical procedures; acquisition, data, analysis and interpretation of data; statistical analysis, manuscript preparation and writing; critical revision; final approval.

"PhD, Division of Coloproctology, Hospital de Clínicas de Porto Alegre, UFRGS, Porto Alegre-RS, Brazil. Analysis and interpretation of data, statistical analysis, manuscript writing, critical revision, final approval.

'I'MD, Postgraduate Program in Surgical Sciences, UFRGS, Porto Alegre-RS, Brazil. Surgical procedures, acquisition of data, statistical analysis, critical revision, final approval.

"VGraduate student, Medical School, UFRGS, Porto Alegre-RS, Brazil. Surgical procedures, acquisition of data.

${ }^{v}$ Associate Professor, PhD, Division of General Surgery, Department of Surgery, Hospital de Clínicas de Porto Alegre, UFRGS, Porto Alegre-RS, Brazil. Conception and design of the study, analysis and interpretation of data, manuscript preparation and writing, critical revision, final approval.

\begin{abstract}
Purpose: To investigate if fluorescein fluorescent test can predict dehiscence in a model of ischemic colonic anastomosis in rats.

Methods: This experimental controlled trial randomly assigned 55 rats to four groups. Anastomoses were performed in non-ischemic colon segments (control group) and in ischemic colon segments measuring 1, 2 or $3 \mathrm{~cm}$ long (groups 1, 2 and 3, respectively). Fluorescein was injected and the tissues were examined under ultraviolet light. Seven days later, a second-look surgery was performed to check for the presence or absence of anastomosis dehiscence.

Results: Twenty-four rats presented anastomotic dehiscence during the second-look surgery. Reticular and nonfluorescent patterns were significantly associated with the occurrence of anastomotic dehiscence. Fluorescein fluorescence had a sensitivity of $95.8 \%$, specificity of $89.2 \%$, positive predictive value of $88.4 \%$, negative predictive value of $96.2 \%$, and accuracy of 92.3\% to predict anastomotic dehiscence.

Conclusion: Fluorescein fluorescent test can accurately predict leak in a model of ischemic colonic anastomosis in rats.
\end{abstract}

Key words: Anastomosis, Surgical. Anastomotic Leak. Fluorescence. Blood Supply. Rats. 


\section{- Introduction}

Surgeries that require anastomosis of the large bowel are among the most commonly performed abdominal procedures in the western world ${ }^{1}$. Ongoing advances in terms of perioperative care and surgical techniques have provided better results in the surgical treatment of patients with colorectal diseases. However, the rate of complications after colorectal surgeries is still high - around 30\% -, and anastomotic dehiscence remains a relevant unsolved problem ${ }^{2-5}$.

There is a general consensus on the key role of blood supply, mainly at the bowel margins, for the proper healing of intestinal anastomosis. Therefore, a rigorous intraoperative evaluation of the intestinal perfusion is essential for the prevention of anastomotic dehiscence ${ }^{1,6}$. Clinical tests to predict the occurrence of anastomotic dehiscence have very low accuracy, with a failure rate up to $60 \%{ }^{4,7-9}$. Several studies have been conducted to find an objective and reliable method of intraoperative evaluation of intestinal blood supply in the last four decades ${ }^{2,3,7,10-14}$. To present date, no method has been accepted as the standard for this matter, however fluorescence tests have gained some attention $^{16-22}$.

Fluorescein fluorescence test is done by means of injection of intravenous sodium fluorescein, followed by examination of target tissues under ultraviolet light in a darkened room. Luminescence clearly differentiates well perfused from ischemic tissues ${ }^{12}$. The sensitivity and specificity of this technique are close to $100 \%{ }^{11,14}$. Currently, fluorescence method to evaluate the perfusion of intestinal anastomoses has been increasingly used in robotic-assisted and laparoscopic colorectal resections, such as left colectomies and rectal ressections.

The aim of this study was to determine the sensitivity, specificity, positive predictive value (PPV) and negative predictive value (NPV) of fluorescein fluorescence test to predict anastomotic dehiscence.

\section{- Methods}

This study was approved by the Research Ethics Committee and the Ethics Committee for the Use of Animals (Protocol 110668) of the Hospital de Clínicas de Porto Alegre. This study has been carried out in accordance with The Code of Ethics of the World Medical Association (Declaration of Helsinki).

Surgical procedures were conducted in the Animal Experimentation Unit of Hospital de Clínicas de Porto Alegre (AEUHCPA). Male Wistar rats, 10 to 12 weeks old, from contemporary litters (275-340g) were purchased from the Vivarium of the Federal University of Pelotas (Pelotas, Brazil). Animals were maintained in groups of four in separate cages in a temperature-controlled room (22 \pm $2 \circ \mathrm{C})$ and 12 hour light-dark cycle. All the animals received free access of water and standard rat chow. The rats were daily monitored by veterinarians from the AEU-HCPA.

This experimental controlled trial randomly assigned rats to four groups. The sample size of each group was calculated based on the results of a pilot study conducted with 20 rats to investigate the rate of anastomotic dehiscence according to the different lengths of intestinal devascularization. With regard to the expected frequency of $45 \%$ of overall anastomosis dehiscence in that study, a sample size of 55 rats was considered sufficient to achieve a sensitivity of $99 \%$ and a specificity of $91 \%$, at $5 \%$ precision for sensitivity and $10 \%$ for specificity and a level of confidence of $95 \%$. The minimum number of rats required for statistical analysis was used in each of the following groups: control group (nonischemic colocolonic anastomosis), and groups 1, 2 and 3 (colocolonic anastomosis in ischemic segments 
of 1,2 and $3 \mathrm{~cm}$-long, respectively) (Figure 1).

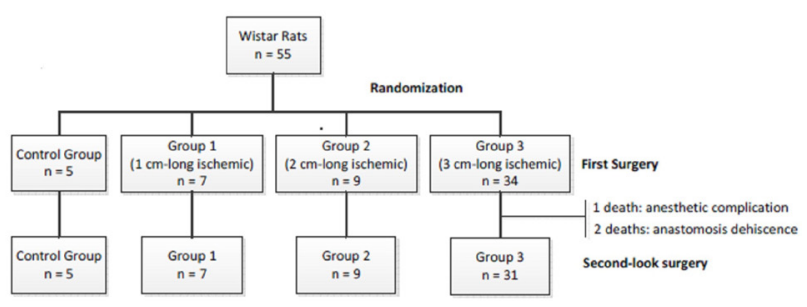

Figure 1 - Study design and randomization of groups.

\section{Anesthesia and surgical procedure}

The rats were weighed and given intraperitoneal injection of ketamine $(90 \mathrm{mg} /$ $\mathrm{kg}$ ) and xylazine (10 mg/kg). After loss of paw withdrawal reflex was confirmed, the animals were fixed to a temperature-controlled operating table and had the abdomen region shaved and aseptically cleaned with 10\% topical povidone-iodine. Sterilized surgical instruments were used for the surgical procedures $^{23}$. All animals underwent midline laparotomy, abdominal exploration and exposure of ascending colon. The control group underwent transversal section of the ascending colon. A straight colocolonic anastomosis was performed with a single layer of continuous suture with 6-0 polypropylene monofilament. In groups 1, 2 and 3, a colon segment of 1-, 2- and 3-cm long, respectively, underwent selective devascularization, as previously described by Griffen24. This method consists of devascularization of the marginal artery at two points, as well as the vasa recti located in-between, using a bipolar cautery ${ }^{1}$. At the midpoint of the devascularized segment, the colon was sectioned and an anastomosis was performed in the same way as described in control group. None of the anastomoses showed clinical signs suggestive of an immediate anastomotic ischemia.

\section{Fluorescein fluorescence test}

All animals underwent fluorescein fluorescence test. Fluorescein fluorescence test is done by injecting fluorescein sodium (1.5 $\mathrm{mg} / 100 \mathrm{mg}$ diluted in saline solution at $3 \mathrm{mg} / \mathrm{mL}$ ) intravenously, followed by examination of target tissues under ultraviolet light (16 watts Wood lamp, Ramsor ${ }^{\circledR}$, São Paulo, Brazil) in a darkened room. The test was conducted immediately after the performance of the anastomosis. The $2-\mathrm{cm}$ colon segments in each side of the anastomosis were evaluated to access the fluorescence pattern using a +4-diopter lens. The fluorescence patterns were classified as homogeneous, reticular, patchy or nonfluorescent ${ }^{12,14}$ (Figure 2).

The abdominal wall was then closed

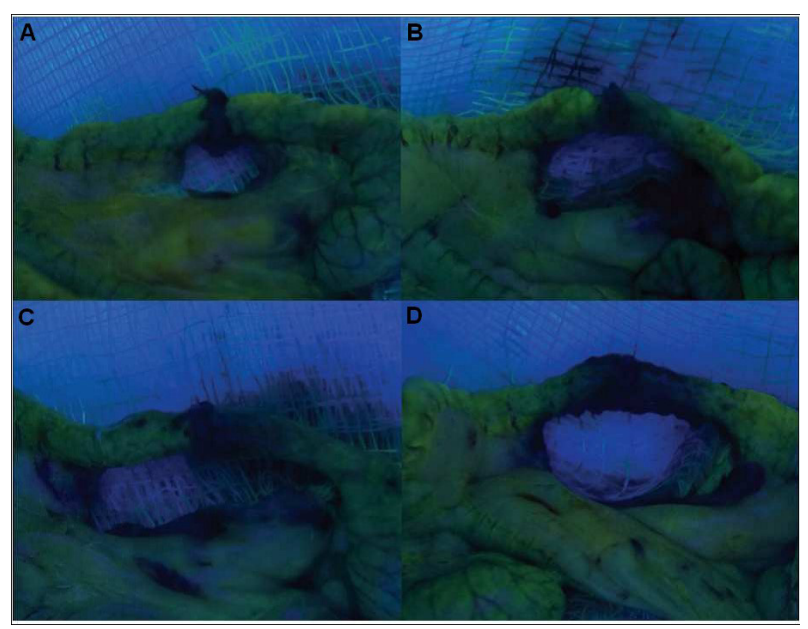

Figure 2 - Fluorescein fluorescence patterns: A) homogeneous; B) reticular; C) patchy; D) nonfluorescent.

with two layers of continuous suture with 4-0 nylon and thereafter an intraperitoneal injection of tramadol hydrochloride $(5 \mathrm{mg} / \mathrm{kg}$ ) was administered for postoperative analgesia. Seven days later, the rats underwent a secondlook surgery for macroscopic re-evaluation of the anastomosis and reassessment of the fluorescein fluorescence test. Surgical findings were classified according to the following 
degrees: grade 1 - ascending colon with normal appearance or minor edema; grade 2 - marked edema or signs of ischemia (purplish color, darkened areas); grade 3 - partially blocked dehiscence or abscess around anastomosis; grade 4 - totally blocked dehiscence or peritonitis due to total or partial dehiscence. Subsequently, the animals were killed by exsanguination.

\section{Statistical analysis}

The results of the descriptive analyses for continuous variables were expressed as means and standard deviations (SD). The results for qualitative variables were reported as absolute frequencies and proportions. Chi-square test was used to analyze comparisons between groups. Mann-Whitney and Kruskal-Wallis tests were used to analyze asymmetrically distributed continuous variables. The level of significance was set at $5 \%$.

\section{Results}

A total of 55 rats were used in this study: five rats in control group, seven rats in group 1 , nine rats in group 2, and 34 rats in group 3. Table 1 presents general data for each group. Rats in group 3 were significantly younger than those in the other groups (78 vs. 78.7 vs. 78.3 vs. 74.2-days-old; $p<0.001)$. There were no statistically significant differences between the groups in terms of baseline and re-intervention weights and surgery duration.

Table 1 - General data for each intervention group.

\begin{tabular}{lcccc} 
& $\begin{array}{c}\text { Control Group } \\
\text { mean }\left(25-75^{\text {th }}\right)\end{array}$ & $\begin{array}{c}\text { Group 1 } \\
\text { mean }\left(25-75^{\text {th }}\right)\end{array}$ & $\begin{array}{c}\text { Group 2 } \\
\text { mean }\left(25-75^{\text {th }}\right)\end{array}$ & $\begin{array}{c}\text { Group 3 } \\
\text { mean }\left(25-75^{\text {th }}\right)\end{array}$ \\
\hline Age (days) & $78(77-79.5)$ & $78.7(77-80)$ & $78.3(77-79.5)$ & $74.2(71.3-79)^{*}$ \\
Baseline weight (g) & $309.2(282-335)$ & $322.3(286-368)$ & $333.5(305-364.5)$ & $316.6(291.5-332.5)$ \\
Surgery duration (min) & $24(22-26.5)$ & $22.4(20-24)$ & $25.9(22.5-28.5)$ & $24.8(23-26.3)$ \\
Re-intervention weight (g) & $291.4(269.5-314)$ & $293(242-340)$ & $311.7(283.5-345)$ & $293.8(268-322.3)$ \\
Re-intervention duration & $10.2(9-11)$ & $9.9(8-11)$ & $10.7(9-11)$ & $10.6(9-12)$ \\
(min) & & & & \\
\hline
\end{tabular}

$* p<0.001$

Three rats died in group 3; one as consequence of anesthetic complication after the first surgery and two due sepsis secondary to anastomotic dehiscence, confirmed at the necropsy. These rats were excluded from the statistical analysis. The fluorescein fluorescence patterns in the first surgery, as well as the surgical findings and fluorescein fluorescence patterns in the second-look surgery are demonstrated in Table 2. All rats in the control group had homogenous fluorescence pattern in both surgeries and normal appearance or minor edema (grade 1) in the second-look surgery. All rats in group
1, except one (reticular pattern), presented homogeneous fluorescence pattern and normal appearance or minor edema of colon (grade 1 ). This sole rat with reticular pattern experienced anastomotic dehiscence and was classified as grade 3 (partially blocked dehiscence or abscess around anastomosis) during the second-look surgery. The majority (77.8\%) of the rats in group 2 presented reticular fluorescence pattern in the first surgery $(p<0.01)$. Most of these rats $(85.7 \%)$ maintained the same fluorescence pattern during the second-look surgery $(p<0.01)$ and none experienced anastomotic dehiscence. 
Rats in group 3 presented mostly patchy or nonfluorescent patterns both in the first and the second-look surgery, respectively $(55.9 \%$ and $29.4 \%, p<0.05 ; 58.1 \%$ and $25.8 \%, p<$
0.01). Twenty-three (74.2\%) rats in group 3 presented partially blocked dehiscence or abscess around anastomosis (grade 3 ) during the second-look-surgery $(p<0.01)$.

Table 2 - Fluorescein fluorescence pattern and surgical results for each intervention group.

\begin{tabular}{|c|c|c|c|c|}
\hline & $\begin{array}{c}\text { Control Group } \\
n(\%)\end{array}$ & $\begin{array}{c}\text { Group } 1 \\
n(\%)\end{array}$ & $\begin{array}{c}\text { Group } 2 \\
n(\%)\end{array}$ & $\begin{array}{c}\text { Group } 3 \\
n(\%)\end{array}$ \\
\hline \multicolumn{5}{|c|}{$\begin{array}{l}\text { First surgery fluorescein } \\
\text { fluorescence pattern }(n=55)\end{array}$} \\
\hline Homogeneous & $5(100)^{*}$ & $6(85.7)^{*}$ & $2(22.2)$ & $0(0)$ \\
\hline Reticular & $0(0)$ & $1(14.3)$ & $7(77.8)^{*}$ & $5(14.7)$ \\
\hline Patchy & $0(0)$ & $0(0)$ & $0(0)$ & $19(55.9)^{*}$ \\
\hline Nonfluorescent & $0(0)$ & $0(0)$ & $0(0)$ & $10(29.4)^{*}$ \\
\hline \multicolumn{5}{|l|}{$\begin{array}{l}\text { Second-look surgery } \\
\text { fluorescein fluorescence } \\
\text { pattern }(n=52)\end{array}$} \\
\hline Homogeneous & $5(100)^{*}$ & $6(85.7)^{*}$ & $3(33.3)$ & $0(0)$ \\
\hline Reticular & $0(0)$ & $1(14.3)$ & $6(67.7)^{*}$ & $5(16.1)$ \\
\hline Patchy & $0(0)$ & $0(0)$ & $0(0)$ & $18(58.1)^{*}$ \\
\hline Nonfluorescent & $0(0)$ & $0(0)$ & $0(0)$ & $8(25.8)^{*}$ \\
\hline \multicolumn{5}{|l|}{$\begin{array}{l}\text { Second-look surgical } \\
\text { findings }(n=52)\end{array}$} \\
\hline Grade 1 & $5(100)^{*}$ & $6(85.7)^{*}$ & $4(44.4)$ & $0(0)$ \\
\hline Grade 2 & $0(0)$ & $0(0)$ & $5(55.6)^{*}$ & $8(25.8)$ \\
\hline Grade 3 & $0(0)$ & $1(14.3)$ & $0(0)$ & $23(74.2)^{*}$ \\
\hline Grade 4 & $0(0)$ & $0(0)$ & $0(0)$ & $0(0)$ \\
\hline Anastomosis dehiscence & $0(0)$ & $1(14.3)$ & $0(0)$ & $23(74.2)$ \\
\hline
\end{tabular}

${ }^{*} p<0.001$

As shown in Table 3, the homogeneous and reticularfluorescence patternsimmediately after the anastomosis construction were significantly associated with anastomotic integrity during the second-look surgery. In contrast, the reticular and nonfluorescent patterns were significantly associated with the occurrence of anastomotic dehiscence.

Table 3 - Incidence of anastomotic dehiscence according to fluorescence pattern in the first surgery.

\begin{tabular}{lcccc} 
& Homogeneous & Reticular & Patchy & Nonfluorescent \\
& $\mathrm{n}(\%)$ & $\mathrm{n}(\%)$ & $\mathrm{n}(\%)$ & $\mathrm{n}(\%)$ \\
\hline No dehiscence & $13(46.4)^{*}$ & $12(42.9)^{*}$ & $3(10.7)$ & $0(0)$ \\
Dehiscence & $0(0)$ & $1(4.2)$ & $14(58.3)^{*}$ & $9(37.5)^{*}$ \\
\hline
\end{tabular}


Due to the similarity of data and same clinical meaning, the results of homogeneous and reticular patterns, as well as those of patchy and nonfluorescent patterns, were combined for calculations of sensitivity, specificity, positive and negative predictive values and accuracy of fluorescein fluorescence for anastomosis dehiscence. Data are shown in Table 4.

Table 4 - Diagnostic accuracy of fluorescein fluorescence test for anastomotic dehiscence.

\begin{tabular}{lcc}
\hline & $\begin{array}{c}\text { Result } \\
(\%)\end{array}$ & $95 \% \mathrm{Cl}$ \\
\hline Sensitivity & 95.8 & $76.9-99.8$ \\
Specificity & 89.2 & $70.6-97.2$ \\
Positive Predictive Value & 88.4 & $68.7-96.8$ \\
Negative Predictive Value & 96.2 & $78.4-99.8$ \\
Accuracy & 92.3 & $83.1-100$ \\
\hline
\end{tabular}

\section{- Discussion}

Anastomotic dehiscence is the "Achilles heel" for colorectal surgery, despite the many technical advances achieved in recent decades. This can be explained by its high incidence and negative impact on the health of the patient (increased morbidity and mortality rates, length of hospital stay, risk of permanent ostoma, poor prognosis in cancer patients, damage on quality of life) and on the socioeconomic status of the population (increased health costs and workplace absence) $)^{25}$. So far, there is no technique or cost-effective method for predicting the occurrence of colorectal anastomotic dehiscence ${ }^{2,3,26}$. Clinical parameters, such as intestine color, the presence of peristalsis, mesenteric pulse, active bleeding have historically demonstrated low accuracy to assess the viability of ischemic bowel $^{12}$. More sophisticated evaluation methods of intestinal perfusion, such as laser Doppler fluxometry, intramural $\mathrm{pH}$, intestinal electromyography, intra-arterial injection of dye and radioactive microspheres, have also been tested ${ }^{12}$. However, these techniques are invasive, expensive or require specialized equipment ${ }^{12}$. The ideal evaluation method of intestinal perfusion should be easily accessed in the operating room, quick to use, have good accuracy, low cost and be minimallyinvasive $^{12}$. The fluorescence method with intravenous administration of fluorescein and examination under ultraviolet light meet all these criteria ${ }^{7,10-12,14}$.

The present study comprised a control group (non-ischemic anastomosis) and three intervention groups with varying degrees of ischemic colonic anastomosis in rats. The objective was to analyze the immediate and delayed patterns of fluorescein fluorescence in each group and to associate these findings with the occurrence of ischemic damage to the large intestine. We described, for the first time in the literature, an accurate method for the evaluation of perfusion of the ischemic colon segments in an experimental model to predict anastomosis dehiscence in rats. This pilot study showed that $3 \mathrm{~cm}$ long segment of the ischemic colon resulted in higher rates of anastomotic dehiscence. Following the recommendations of the Ethics Committee for the Use of Animals, group 3 had a greater number of rats than the others to ensure that the objective of this study was achieved with reduced number of deaths. The rats in group 3 were significantly younger compared to the other groups. No significant differences were observed between the average weight of the animals, which is an indirect indicator of nutritional status, a factor involved in the occurrence of anastomotic dehiscence in rats $^{27}$. However, the highest rate of anastomotic dehiscence in group 3 could not be attributed to the fact that these rats were younger compared to those in the other groups. On the contrary, this finding can be attributed to the greater extent of colonic ischemia resulting from the intervention in group 3, as objectively described using the 
fluorescein fluorescence method. In fact, more than $80 \%$ of the rats in group 3 showed signs of critical tissue ischemia (patchy or non fluorescent pattern) both in immediate and late evaluation of anastomosis perfusion. These fluorescence patterns represent the total and regional disruption of blood flow of the colon, respectively. Both patterns were statistically associated with the finding of ischemic tissue damage in second-look surgery, particularly the anastomotic dehiscence. The analysis of the fluorescence test results showed high levels of sensitivity, specificity, PPV, NPV and accuracy of fluorescein fluorescence for anastomotic dehiscence.

This performance makes the fluorescein fluorescence test an appropriate method to indicate correctly the revision and re-confection of an ischemic colonic anastomosis, therefore, decreasing the rate of anastomotic dehiscence. It also allows the surgeon to accurately judge the adequacy of the perfusion of a colonic anastomosis, avoiding unnecessary revision and re-confection. It should be reminded that these results were observed in colonic anastomosis without clinical evidence of ischemic suffering immediately after its confection and should not be extrapolated to cases of clinically detectable ischemia.

In the last decades, several authors have investigated the use of fluorescence techniques to evaluate the feasibility of anastomosis in the left colon and rectum in both conventional and minimally-invasive surgeries (laparoscopic and robotic $)^{9,28}$. These publications corroborate our findings that the fluorescence technique is able to accurately identify colonic anastomosis with critical ischemia, which requires modifications of surgical procedures (e.g. confection of a temporary deviation ostoma or, more often, an extension of the bowel resection and confection of a new anastomosis) to reduce the rate of anastomotic dehiscence ${ }^{9}$. Unlike the intraoperative near infrared fluorescence adopted in minimally-invasive surgery, especially the imaging platform - named Firefly system - integrated into the da Vinci $\operatorname{robot}^{28}$, the fluorescein fluorescence technique under ultraviolet light is extremely cheap, making it an affordable diagnostic test to be used in developing countries.

The study has some limitations. First, we did not perform a histopathological study of the anastomosis for comparative analysis with the fluorescence test findings. Second, no other evaluation method of intestinal perfusion was used for comparison with the fluorescence test. Finally, there was no study on the eventual outcomes of the possible changes in surgical procedures, resulting from the interpretation of the fluorescence test findings. Even with these limitations, our study validated an easy to use, low cost and highly accurate method to predict ischemic colonic anastomosis in rats. Further studies are required to confirm whether these findings may be reproduced and are beneficial for humans.

\section{- Conclusions}

Fluorescein fluorescent test accurately predicts leaks in a model of ischemic colonic anastomosis in rats. Notably, the reticular and nonfluorescent patterns are associated with the occurrence of anastomotic dehiscence

\section{References}

1. Irkorucu O, Ucan BH, Cakmak GK, Emre AU, Tascilar O, Ofluoglu E, Bahadir B, Karakaya K, Demirtas C, Ankarali H, Kertis G, Pasaoglu H, Comert M. Does sildenafil reverse the adverse effects of ischemia on ischemic colon anastomosis: yes, 'no'. Int J Surg. 2009 Feb;7(1):39-43. doi: 10.1016/j. ijsu.2008.10.003.

2. Shogan BD, Carlisle EM, Alverdy JC, Umanskiy K. Do we really know why colorectal anastomoses leak? J Gastrointest Surg. 2013 Sep;17(9):1698-707. doi: 10.1007/s11605013-2227-0.

3. Sultan R, Chawla T, Zaidi M. Factors affecting anastomotic leak after colorectal 
anastomosis in patients without protective stoma in tertiary care hospital. J Pak Med Assoc. 2014 Feb;64(2):166-70. PMID: 24640806.

4. Arriaga $A F$, Lancaster RT, Berry $W R$, Regenbogen SE, Lipsitz SR, Kaafarani HMA, Elbardissi AW, Desai P, Ferzoco SJ, Bleday $R$, Breen $E$, Kastrinakis WV, Rubin MS, Gawande AA. The better colectomy project: association of evidence-based best-practice adherence rates to outcomes in colorectal surgery. Ann Surg. 2009 Oct;250(4):507-13. doi: 10.1097/SLA.0b013e3181b672bc.

5. Hammond J, Lim S, Wan Y, Gao X, Patkar A. The burden of gastrointestinal anastomotic leaks: an evaluation of clinical and economic outcomes. J Gastrointest Surg. 2014 Jun;18:1176-85. doi: 10.1007/s11605-0142506-4.

6. Carter MS, Fantini GA, Sammartano RJ, Mttsudo S, Silverman DG, Boley SJ. Qualitative and quantitative fluorescein fluorescence in determining intestinal viability. Am J Surg. 1984 Jan;147(1):117-23. PMID: 6691537.

7. Malafaia O, Brioschi ML, Aoki SMS, Dias FG, Gugelmin BS, Aoki MS, Aoki YS. Infrared imaging contribution for intestinal ischemia detection in wound healing. Acta Cir Bras. 2008 Nov-Dec;23(6):511-9. PMID: 19030750.

8. Karliczek A, Harlaar NJ, Zeebregts CJ, Wiggers T, Baas PC, Dam GM. Surgeons lack predictive accuracy for anastomotic leakage in gastrointestinal surgery. Int J Colorectal Dis. 2009 May;24(5):569-76. doi: 10.1007/ s00384-009-0658-6.

9. Jafari MD, Lee KH, Halabi WJ, Mills SD, Carmichael JC, Stamos MJ, Pigazzi A. The use of indocyanine green fluorescence to assess anastomotic perfusion during robotic assisted laparoscopic rectal surgery. Surg Endosc. 2013 Aug;27(8):3003-8. doi: 10.1007/s00464-013-2832-8.

10.Paral J, Subrt Z, Lochman P, Ferko A, Dusek T, Slaninka I, Cecka F, Louda M, Romzová M, Jon B, Kaska M. Peroperative diagnostics of acute bowel ischemia using ultraviolet light and fluorescein dye. Rozhl Chir. 2009
Oct;88(10):590-5. PMID: 20052943.

11.Paral J, Ferko A, Plodr M, Raupach J, HadziNikolovD, DolezalD, ChovanecV.Laparoscopic diagnostics of acute bowel ischemia using ultraviolet light and fluorescein dye: an experimental study. Surg Laparosc Endosc Percutan Tech. 2007 Aug;17(4):291-5. doi: 10.1097/SLE.0b013e3180dc9376.

12.Stolar CJ, Randolph JG. Evaluation of ischemic bowel viability with a fluorescent technique. J Pediatr Surg. 1978 Jun;13(3):221-5. PMID: 671186.

13. Horgan PG, Gorey TF. Operative assessment of intestinal viability. Surg Clin North Am. 1992 Feb;72(1):143-55. PMID: 1731381.

14.Bulkley GB, Zuidema GD, HamiltonSR, O'Mara CS, Klacsmann PG, Horn SD. Intraoperative determination of small intestinal viability following ischemic injury: A prospective, controlled trial of two adjuvant methods (doppler and fluorescein) compared with standard clinical judgment. Ann Surg. 1981 May;193(5):628. PMID: 7016053.

15.Diana $M$, Agnus V, Halvax $P$, Liu $Y-Y$, Dallemagne B, Schlagowski A-I, Geny B, Diemunsch $\mathrm{P}$, Lindner $\mathrm{V}$, Marescaux J. Intraoperative fluorescence-based enhanced reality laparoscopic real-time imaging to assess bowel perfusion at the anastomotic site in an experimental model. Br J Surg. 2015 Jan;102:e169-76. doi: 10.1002/bjs.9725.

16.Santos Júnior JCM. Post-surgical complications of the colorectal anastomosis. Rev Bras Coloproct. 2011 JanMar;31(1):98-106.

17. Urbanavicius L, Pattyn P, Putte $D$, Venskutonis D. How to assess intestinal viability during surgery: a review of techniques. World J Gastrointest Surg. 2011 May;3(5):59-69. doi: 10.4240/wjgs.v3.i5.59.

18. Koruda MJ, Rolandelli RH. Experimental studies on the healing of colonicanastomoses. J Surg Res. 1990 May;48(5):504-15. PMID: 2191171.

19.Hendriks T, Mastboom WJ. Healing of experimental intestinal anastomoses. Parameters for repair. Dis Colon Rectum. 1990 Oct;33(10):891-901. PMID: 2209281. 20.Uzun H, Konukoglu D, Nuri MK, Ersoy EY, 
Özçevik S, Yavuz N. The effects of sildenafil citrate on ischemic colonic anastomotic healing in rats: its relationship between nitric oxide and oxidative stress. World J Surg. 2008 Sep;32(9):2107-13. doi: 10.1007/ s00268-008-9661-2.

21.Posma LAE, Bleichrodt RP, van Goor $H$, Hendriks T. Transient profound mesenteric ischemia strongly affects the strength of intestinal anastomoses in the rat. Dis Colon Rectum. 2007 Jul;50(7):1070-9. doi: 10.1007/s10350-006-0822-9.

22. Kaya Y, Coskun T, Ayhan S, Kara E, Sakarya A, $\operatorname{Var} A$. The effect of tadalafil on anastomotic healing in ischemic small intestine in rats. Surg Today. 2010 Jun;40(6):555-60. doi: 10.1007/s00595-010-4229-9.

23. Marjanovic G, Holzner P, Kulemann B, Kuesters S, Karcz WK, Timme S, Zur Hausen A, Baumann T, Hopt UT, Obermaier R, Hoeppner J. Pitfalls and technical aspects during the research of intestinal anastomotic healing in rats. Eur Surg Res. 2010;45(3-4):314-20. doi: 10.1159/000320768.

24.Griffen TS, Hagihara PF. Ischemic colitis in rats. Dis Colon Rectum. 1982 Oct;25(7):63840. PMID: 7128361.

25.BruceJ, KrukowskiZH, Al-KhairyG, RussellEM,
Park KG. Systematic review of the definition of anastomotic leak after gastrointestinal surgery. Br J Surg. 2001 Sep;88:1157-68. doi: 10.1046/j.0007-1323.2001.01829.x.

26.Dekker JWT, Liefers GJ, de Mol van Otterloo JC, Putter $\mathrm{H}$, Tollenaar RA. Predicting the risk of anastomotic leakage in left-sided colorectal surgery using a colon leakage score. J Surg Res. 2011 Mar;166(1):e27-34. doi: 10.1016/j.jss.2010.11.004.

27.Domínguez JGL, Athié AAJ, Mijares GJM, Cárdenas LE, Pérez RE. Effects of malnutrition on the colonic anastomosis in the rat. Cir Gen. 2001 Apr-Jun;23(2):81-6.

28.Bae SU, Baek SJ, Hur H, Baik SH, Kim NK, Min BS. Intraoperative near infrared fluorescence imaging in robotic low anterior resection: three case reports. Yonsei Med J. 2013 Jul;54(4):1066-9. doi: 10.3349/ ymj.2013.54.4.1066.

\section{- Acknowledgement}

The staff of the Animal Experimentation Unit and Experimental Pathology Unit, Research Center, Hospital de Clínicas de Porto Alegre for their support.

\section{Correspondence:}

Tiago Leal Ghezzi

Hospital de Clinicas de Porto Alegre, Disciplina

de Coloproctologia

Rua Ramiro Barcelos, 2350/600

90035-903 Porto Alegre - RS Brasil

Tel.: (55 51)9725-6265

Fax: (55 51)3311-8151

tlghezzi@terra.com.br

Received: Feb 20, 2017

Review: Apr 18, 2017

Accepted: May 16, 2017
Conflict of interest: none

Financial source: FIPE/HCPA

\begin{abstract}
${ }^{1}$ ResearchperformedatAnimal Experimentation Unit, Hospital de Clínicas de Porto Alegre (AEUHCPA), Universidade Federal do Rio Grande do Sul (UFRGS), Porto Alegre-RS, Brazil. Part of Master degree thesis, Postgraduate Program in Surgical Sciences. Tutor: Oly Campos Corleta.
\end{abstract}

